\title{
EDITORIAL \\ Revistas USB y tendencias de la ciencia
}

https://doi.org/10.17081/just.22.32.2989

\section{Ferney Asdrúbal Rodríguez-Serpa ${ }^{1}$}

Los sistemas de publicaciones en Colombia y en el mundo posibilitan hoy determinar las tendencias de la ciencia en diferentes niveles de desarrollo científico, pero sobre todo en distintos escenarios geográficos de conformidad a las necesidades demandadas en cada contexto. De otra parte, estas tendencias también se determinan por los intereses compartidos de las microcomunidades científicas, es decir las que se validan desde el envío del producto científico, hasta el papel de los árbitros o pares expertos que finalmente definen a través del rigor evaluativo, lo que se recomienda publicar.

Esta última apreciación es realmente compleja a la hora de determinar las tendencias de las ciencias a través de las revistas seriadas, pues para el caso colombiano la relación de pares endógenos y exógenos es de prelación de estos últimos y como es de suponer, un elevado número de pares externos implica un universo disperso territorialmente de su papel como orientadores de una comunidad científica; razón que se constituye en una falacia: pensar sobre la idea de construcción de comunidad científica a partir de ellos o con su apoyo.

No se pretende ser exotérico, ni chamán en este editorial, pero como dice la investigadora mexicana Karla Rodríguez-Burgos, en la ciencia siempre ha estado presente "la mano negra del investigador"; en este caso se pensaría en la Mano negra del editor", pues es el finalmente quien determina qué se debe publicar, pues es la autoridad suprema del proceso editorial y del manejo y control de las políticas de instrucción para los autores, y quien en últimas conoce mejor los criterios éticos. No obstante, no se valida esta postura, pero todo hombre de ciencia debe necesariamente cuestionar y sospechar de su propio trabajo y del de sus colegas.

Una salida diplomática a lo anterior son los famosos monográficos, que si bien determinan una tendencia de producción científica, su interés lo determina el editor y su comité editorial. Sobre el particular es válido preguntarnos metodológicamente ¿Cuál es el criterio que determina un mono-

1 Abogado, Sociólogo, Mg. en Derecho Procesal. Doctorante en Filosofía con orientación en Ciencias Políticas de la Universidad Autónoma de Nuevo León. Monterrey-México. Docente-Investigador de pregrado y postgrado. Integrante de la Red Iberoamericana de justicia alternativa, transicional y restaurativa, Red de Justicia ATR. Editor Revista Justicia. ORCID ID: 0000-0002-8197-7010. rodriguezserpaabogados@gmail.com 
gráfico? ¿a qué intereses responden? ¿son estrategias de visibilidad de un programa de postgrado?

Lo cierto en todo caso es que la validez de una tendencia no la determina una revista científica, sino múltiples revistas sin diálogo entre editores, de modo que se garantice la autonomía e independencia del análisis de tendencias de producción científica. En todo caso, para lo propuesto en este editorial, se cree que es posible resaltar dicha sentencia a través de la singularidad de las revistas científicas de la Universidad Simón Bolívar. Queda a criterio del lector confirmar si estamos equivocados o somos oportunos con las orientaciones que ofrecemos a la comunidad de académicos y científicos con esta revista, con Educación y Humanismo, con Psicogente, y con Desarrollo Gerencial.

De conformidad con lo anterior, en la Revista Desarrollo Gerencial se destacan las investigaciones sobre las empresas familiares, como "Protocolos: un instrumento para mediar conflictos en empresas familiares" (Giuseppe \& Pérez, 2015) y “Autotomía caudal como estrategia gerencial para el cambio organizacional en empresas familiares" (El Kadi, Pelekais, Robles \& Leal, 2015). Por su parte, en la Revista Justicia, se subrayan los estudios sobre "La verdad y la justicia frente a la prueba en el proceso penal" (Vicuña \& Castillo, 2015) y el trabajo de Mosquera (2015), sobre "Derechos de las minorías sexuales: retos contemporáneos de la resocialización".

Y finalmente, en la Revista Educación y Humanismo resultan relevantes los estudios sobre "Revisión de las evaluaciones adaptativas computarizadas, (CAT)", (2014, López, Sanmartín \& Mendez), el trabajo de Villalba (2016), sobre "La convivencia escolar en positivo", del mismo modo se destacan en la Revista Psicogente los trabajos de Enriquez, Fajardo, y Garzón (2015), sobre "Una revisión general a los hábitos y técnicas de estudio en el ámbito universitario" y el estudios sobre "Creencias irracionales, síndrome de Burnout y adicción al trabajo en las organizaciones” (2016, Polo, Santiago, Navarro \& Alí).

\section{REFERENCIAS}

El Kadi, O., Pelekais, C., Robles, M. \& Leal, M. (2015). Autotomía caudal como estrategia gerencial para el cambio organizacional en empresas familiares. En Desarrollo Gerencial. Revista de la Facultad de Ciencias Económicas, Administrativas y Contables, 7(1), 68-84.

Enríquez, M., Fajardo, M. \& Garzón, F. (2015). Una revisión general a los hábitos y técnicas de estudio en el ámbito universitario. Psicogente, 18(33), 166-187. http://doi.org/10.17081/psico.18.33.64

Giuseppe, V. \& Pérez, M. (2015). Protocolos: un instrumento para mediar conflictos en empresas familiares. En Desarrollo Gerencial. Revista de la Facultad de Ciencias Económicas, Administrativas y Contables, 7(2), 81-99. http://dx.doi.org/10.17081/dege.7.2.1182

López, R., Sanmartín, P. \& Méndez, F. (2014). Revisión de las evaluaciones adaptativas computarizadas (CAT). En Revista Educación y Humanismo, 16(26), 27-40.

Mosquera, J. (2015). Derechos de las minorías sexuales: retos contemporáneos de la resocialización. 
En Justicia, 28, 121-138. http://dx.doi.org/10.17081/just.20.28.1044

Polo, J. D., Santiago, V., Navarro, M. C. \& Alí, A. (2016). Creencias irracionales, síndrome de Burnout y adicción al trabajo en las organizaciones. Psicogente, 19(35), 148-160. http://doi. org/10.17081/psico.19.35.1215

Vicuna, M. \& Castillo, S. (2015). La verdad y la justicia frente a la prueba en el proceso penal. En Justicia, 27, 118-134. http://doi.org/10.17081/just.3.27.323

Villalba, J. (2016). La convivencia escolar en positivo. En Educacion y Humanismo, 18(30), 92-106. http://dx.doi.org/10.17081/eduhum.18.30.1324 